\title{
DEFORMATION MONITORING AND ANALYSIS OF LSP LANDSLIDE BASED ON GBINSAR
}

\author{
Lv Zhou $^{1,2,3}$, Jiming Guo ${ }^{1,2, *}$, Fei Yang ${ }^{1,2}$ \\ ${ }^{1}$ School of Geodesy and Geomatics, Wuhan University, Wuhan 430079, China - (zhoulv_whu@163.com, jmguo@sgg.whu.edu.cn, \\ fyang_sgg@qq.com) \\ ${ }^{2}$ Key Laboratory of Precise Engineering and Industry Surveying of National Administration of Surveying, Mapping and \\ Geoinformation, Wuhan University, Wuhan 430079, China \\ ${ }^{3}$ Guangxi Key Laboratory for Spatial Information and Geomatics, Guilin University of Technology, Guilin 541004, China
}

KEY WORDS: GBInSAR; IBIS-L; SFCW technique; landslide deformation monitoring; time series analysis

\begin{abstract}
:
Monitoring and analyzing the deformation of the river landslide in city to master the deformation law of landslide, which is an important means of landslide safety assessment. In this paper, aiming at the stability of the Liu Sha Peninsula Landslide during its strengthening process after the landslide disaster. Continuous and high precision deformation monitoring of the landslide was carried out by GBInSAR technique. Meanwhile, the two-dimensional deformation time series pictures of the landslide body were retrieved by the time series analysis method. The deformation monitoring and analysis results show that the reinforcement belt on the landslide body was basically stable and the deformation of most PS points on the reinforcement belt was within $1 \mathrm{~mm}$. The deformation of most areas on the landslide body was basically within $4 \mathrm{~mm}$, and the deformation presented obvious nonlinear changes. GBInSAR technique can quickly and effectively obtain the entire deformation information of the river landslide and the evolution process of deformation.
\end{abstract}

\section{INTRODUCTION}

In many cities of China, there are rivers passing through them. The landslides caused by instability of river slopes poses a serious threat to national economic construction and human life and property safety. Monitoring and analyzing the deformation of river landslide in city to master the deformation law of landslide, which is an important means of landslide safety assessment.

For monitoring and analyzing river landslide deformation, various conventional deformation monitoring methods are widely used, which include levelling (Carminati et al., 2002; Psimoulis et al., 2009), Global Navigation Satellite System (GNSS) (Poland et al., 2006; Baldi et al., 2009), layer-wise mark measurements, piezoelectric accelerometers (Chan et al., 2006), and geological and geophysical investigation methods (Anell et al., 2009). These methods are accurate and reliable, but they usually evaluate the safety of river landslides by retrieving and analyzing only the deformation of several feature points on the landslide body. As a result, effective monitoring and analysis of the overall deformation are difficult. In addition, these methods are limited when used to monitor high-risk river landslides because physical contact is required with the monitored landslides.

In recent years, the interferometric synthetic aperture radar (InSAR) technique (Amelung et al., 1999; Motagh et al., 2008; Chaussard et al., 2013), a non-contact measurement method, has been recognized as an effective low-cost method for monitoring and analyzing the deformation of landslide (Zhao et al., 2012; Schlögel et al., 2015). The limitations of conventional deformation monitoring methods can be overcome by the InSAR technique because of its non-invasiveness, high spatial resolution and temporal resolution. However, due to limitations related to the satellite platform of the InSAR technique (e.g., low temporal resolution, geometrical distortion, and large distance between the sensor and monitored landslide) (Biawas et al., 2017; Zhou et al., 2017), this technique cannot be used for deformation monitoring of river landslides with highaccuracy and monitoring of rapid movements. To overcome the disadvantages of InSAR technique, the ground-based synthetic aperture radar interferometry (GBInSAR) technique was proposed (Farrar et al., 1999; Tarchi et al., 2000).

The GBInSAR can realize small regional-scale continuous deformation monitoring based on the stepped frequencies continuous wave (SFCW) technique, synthetic aperture radar (SAR) technique and interferometry technique (Ventisette et al., 2012; Macedo et al., 2017). The GBInSAR technique can monitor the deformation of the river landslide with highaccuracy measurements and high temporal-spatial resolution in real time.

In this study, aiming at the stability of the Liu Sha Peninsula (LSP) Landslide during its strengthening process after the landslide disaster, the continuous and high precision deformation monitoring of the LSP landslide was carried out by GBInSAR technique. Meanwhile, the continuous deformation monitoring and analysis of the LSP landslides in the strengthening process were carried out based on the combination of GBInSAR and time series analysis method.

\section{METHODOLOGY}

Two-dimensional SAR images of the monitoring area were obtained through SFCW technique and SAR technique, the obtained image contains amplitude and phase information, and the geometric distance between the radar and monitoring target is reflected in the phase information of the SAR image

\footnotetext{
* Corresponding author
} 
(Pieraccini et al., 2013; Monserrat et al., 2014). The displacement between the radar and target can be computed with the interferometry technique by using the phase changes in SAR images collected at different times (Gentile and Bernardini 2010; Takahashi et al., 2013)

\subsection{The SFCW technique}

SFCW is a kind of radar pulse signal whose frequency changes stepwise. SFCW radar sensor generates $\mathrm{N}$ continuous frequency sequences according to step frequency $\Delta f$, and then forms SFCW radar signal. The time-frequency domain change of SFCW radar signal is shown in Figure 1. For pulsed radar, the high resolution in the range direction is achieved by transmitting a narrow pulse width pulse signal, and the resolution in the range direction $\Delta R$ and the radar pulse width $\tau$ satisfy the following relationship (Carmelo and Giulia, 2010):

$$
\Delta R=\frac{c \tau}{2}
$$

where $c$ is the speed of light in the vacuum. Due to $\tau B=1$, the range resolution can be expressed as:

$$
\Delta R=\frac{c}{2 B}
$$

As can be seen from Figure $1, B=(N-1) \Delta f$ is the bandwidth of the radar signal.

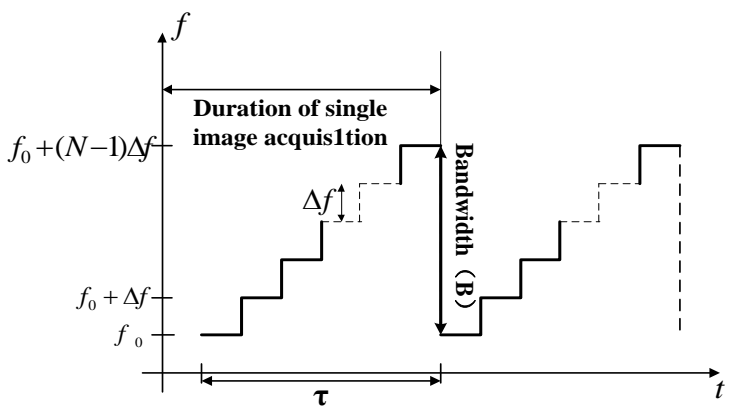

Figure 1. SFCW time-frequency domain change

\subsection{The SAR technique}

SAR technique uses a short antenna to produce a long aperture antenna by modifying the data recording and processing techniques. The radar control unit slides in a "stop and walk" moving mode along the linear guide unit. At the same time, the radar control unit transmits and receives signal data at each pause. Then all the received single image data are compressed into a two-dimensional SAR image, and its azimuth resolution can be expressed as (Rödelsperger et al., 2010):

$$
\Delta \theta=\frac{\lambda}{2 L}
$$

Where $\lambda$ is the electromagnetic wave wavelength, $L$ denotes the effective length of radar control unit sliding on the linear slide.

\subsection{The interferometry technique}

Since the ground-based SAR is a zero-baseline observation, there will be no influence of the flat terrain effect and the terrain effect in the interferometric phase model, and the difference interferometric phase model is obtained by comparing the phase information of the target object at different times (Bardi et al., 2014):

$$
\phi_{\mathrm{int}}=\frac{4 \pi d_{\text {defo }}}{\lambda}+\phi_{\text {atm }}+\phi_{\text {noise }}
$$

Where $\phi_{\text {int }}$ is the interferometric phase, $\phi_{\text {atm }}$ denotes the phase component produced by atmospheric disturbance, and $\phi_{\text {noise }}$ represents the noise phase. After removing the phase component caused by the atmospheric effect and noise phase component, the line-of-sight deformation of the target object can be obtained from equation (4).

\section{EXPERIMENT AND RESULT ANALYSIS}

\subsection{Monitored object and measurement campaign}

The monitored object is the LSP Landslide, which lies on the north shore of the Yongjiang River in Nanning, China, as shown in Figure 2. The latest landslide time of the LSP Landslide was 2014. At this time, the maximum width of the landslide was approximately 200 meter, the thickness of the slide body was more than 15 meters, and the slipping soil was about 40 thousand cubic meters. The LSP Landslide has began to been reinforced since 2016, and a bridge and several concrete reinforcement belts have been built on the landslide body as of the monitoring time. The concrete reinforcement belts are basically parallel to the bridge.

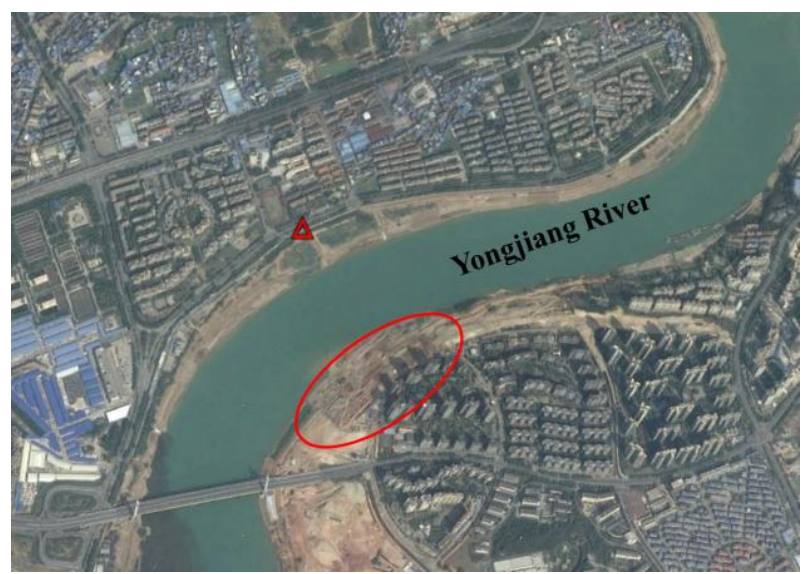

Figure 2. The location of LSP landslide. The red triangle denotes the location of the IBIS-L system, the red ellipse shown in the Figure 2 is the monitored object.

In this study, we adopted the Image by Interferometric Survey of Landslides (IBIS-L) system to monitor the LSP Landslide. The IBIS-L system was rigidly fixed on a stable place (the red triangle shown in Figure 2), which was located in the levee of the south shore of the Yongjiang River. The distance between IBIS-L system and landslide body was approximately 420 meter. The IBIS-L interferometric radar was configured to monitor the LSP Landslide up to a distance of $900 \mathrm{~m}$ with a sampling 
interval of $6 \mathrm{~min}$. The IBIS-L deformation monitoring was carried out from 24 September 2017 to 25 September 2017. Table 1 listed the main configuration parameters of the measurement campaign.

\begin{tabular}{cc}
\hline Parameter & Value \\
\hline Vertical tilt & $0^{\circ}$ \\
Maximum range & $900 \mathrm{~m}$ \\
Resolution in range & $0.5 \mathrm{~m}$ \\
Resolution in azimuth & $4.4 \mathrm{mrad}$ \\
Antenna type & Type3 (Azimuth $17^{\circ}$ Vertical $15^{\circ}$ ) \\
Start time & $15: 18$ September 24, 2017 \\
End time & $15: 00$ September 25, 2016 \\
\hline
\end{tabular}

Table 1. Configuration for the measurement campaign

\subsection{IBIS-L microwave interferometer}

The IBIS-L system developed by Italy IDS company was adopted to monitor the deformation of the LSP landslides. The system is mainly composed of a radar unit, a personal computer (PC) control unit, a linear rail unit and a power supply unit. Each unit of the system is shown in Figure 3.

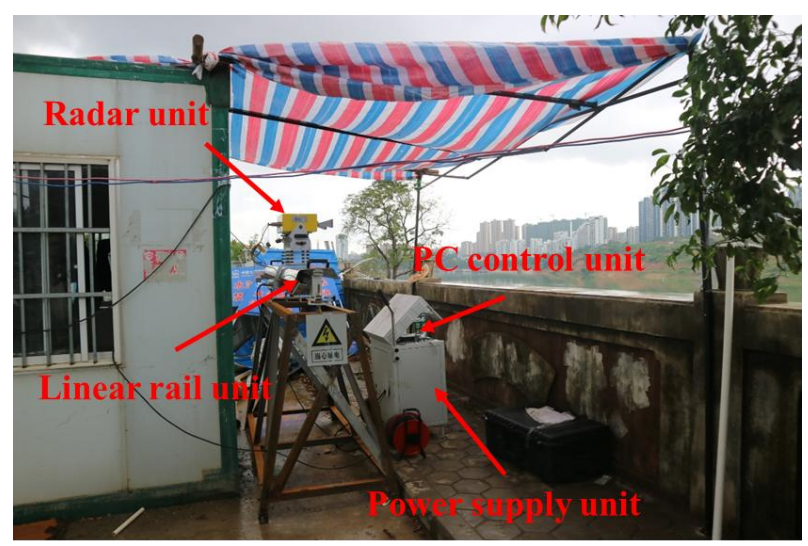

Figure 3. View of the IBIS-L system

The IBIS-L system uses the radar control unit to transmit SFCW to obtain the range resolution information of the monitored scene. At the same time, the radar control unit slides on the linear rail to form a synthetic aperture radar to obtain the high-resolution information in the azimuth direction. Then, twodimensional ground-based SAR images of the monitoring scene can be generated. Finally, the radar line-of-sight deformation of each pixel unit in the ground-based SAR images acquired at different time points is obtained by interferometry technique.

\subsection{Landslide monitoring results and analysis}

In order to accurately extract the landslide deformation information based on the monitoring data, we first selected the PS points of the study area based on multi thresholds, i.e., the coherence coefficient, the thermal signal-to-noise ratio (SNR) and the phase stability. Then, the deformation phase information of the selected PS points was extracted based on time series interference processing. We selected 4 stable points which are outside the monitored landslide as control points, and adopted multi control point correction method to remove the phase component of atmospheric disturbance and noise phase in interferometric phase. Finally, the accurate deformation information of the LSP Landslide was achieved.

Figure 4 shows the thermal SNR of the radar monitoring area. The reflection of the reflector in the monitoring area can be seen from Figure 4 . It can be seen from Figure 4 that the thermal SNR of the landslide area is basically greater than $30 \mathrm{~dB}$, which means that the quality of the SAR image data collected this time is good; the thermal SNR of the concrete reinforcement belts parallel to the bridge on the landslide body are relatively weak because these reinforcement belts are lower than the surrounding soil and the radar signal is blocked.

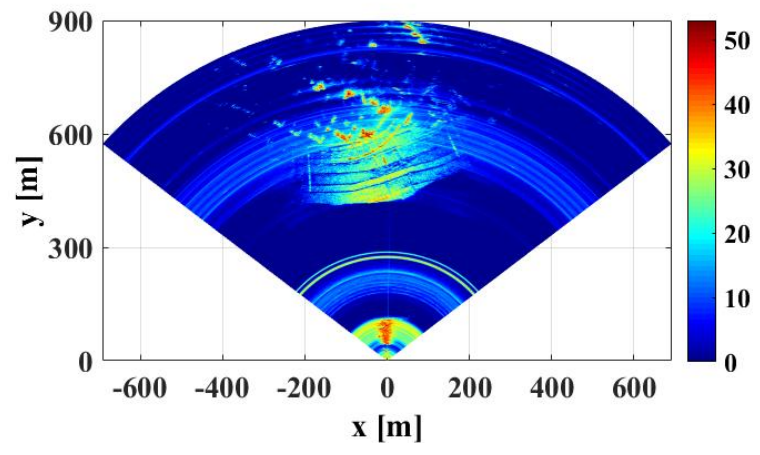

Figure 4. Power image of the monitoring area

In this study, to investigate the overall deformation evolution process of the LSP landslide, a two-dimensional deformation time series analysis of the LSP landslide area was carried out, the result is shown in Figure 5.
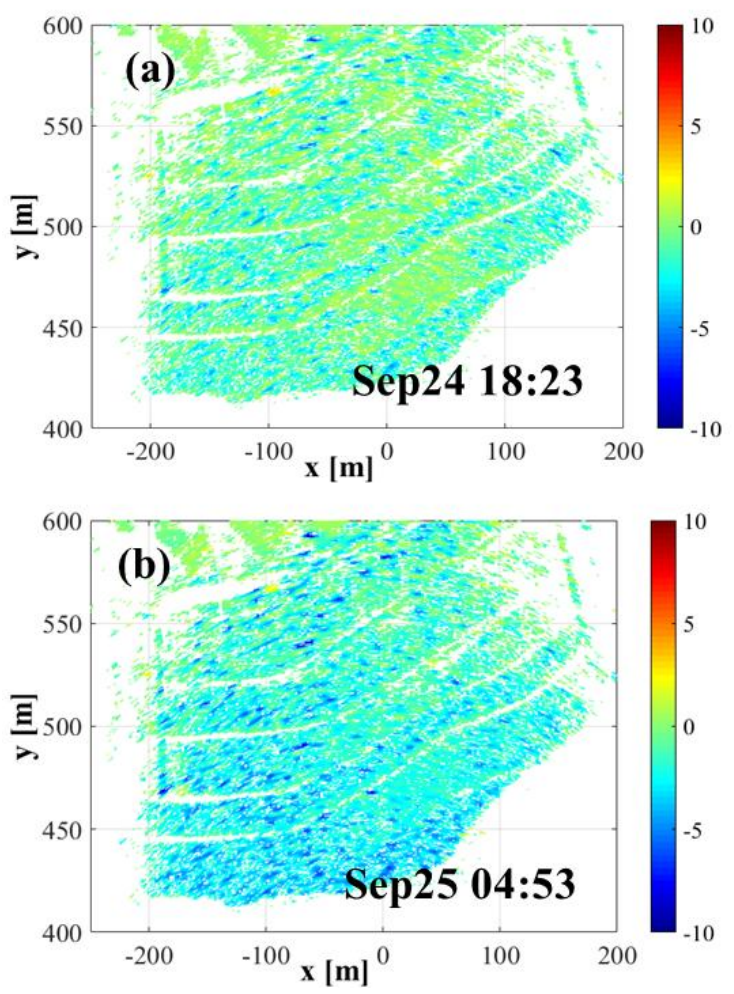

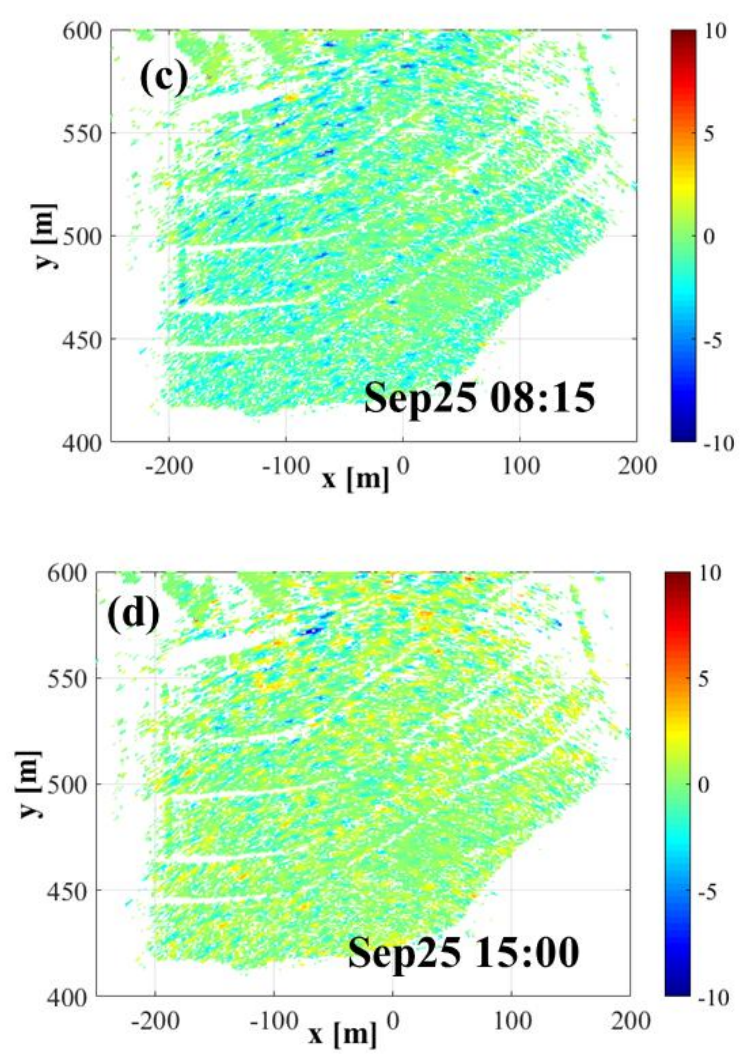

Figure 5. The two-dimensional deformation time series maps of the LSP landslide during the monitoring

Figure 5 shows the two-dimensional deformation maps of the LSP landslide body area after monitoring for approximately $3 \mathrm{~h}$, $14 \mathrm{~h}, 17 \mathrm{~h}$, and $24 \mathrm{~h}$. It can be seen from Figure 5 that the overall deformation value of the landslide body reaches a maximum after monitoring for about $14 \mathrm{~h}$ (Figure $5 \mathrm{~b}$ ), and the deformation value of some monitoring points are close to $10 \mathrm{~mm}$. Due to signal obstruction, almost no PS points were detected in the concrete reinforcement belts parallel to the bridge. However, the PS points near the reinforcement belts are basically stable, and the deformation of most PS points are within $1 \mathrm{~mm}$, indicating that the reinforcement belt on the landslide body is basically in a stable state. Meanwhile, part of the deformation of the landslide body near the Yongjiang River is slightly larger than the upper part of the landslide body. During the monitoring period, the landslide body shown non-linear deformation. The deformation of the landslide body occurred after approximately $3 \mathrm{~h}$, and the maximum deformation was about $2 \mathrm{~mm}$, and then the deformation gradually increased. At 25 September 04:53, the deformation of the landslide body reached the maximum value during the monitoring period, and then the deformation of the landslide gradually decreased. According to the above analysis, the deformation in most parts of the LSP landslide is basically within $4 \mathrm{~mm}$, and the deformation of the landslide presented nonlinear changes.

\section{CONCLUSION}

In this paper, we studied the basic principles of GBInSAR and its key techniques such as SFCW and SAR. In order to study the stability of LSP landslide during the reinforcement process after landslide disaster, combining GBInSAR technique and time series analysis method to conduct continuous deformation monitoring and analysis of the LSP landslide in the process of reinforcement. The results show that the reinforcement belts on the landslide body are basically in a stable state. Other areas of the landslide body are basically bare soil, and there is still a small amount of deformation (basically within $4 \mathrm{~mm}$ ) in these areas. And the deformation shows relatively strong non-linear changes. The two-dimensional deformation time-series information of the river landslides can be obtained through GBInSAR, which can provide regional overall deformation data for the stability assessment of the river landslides in the reinforcement process.

\section{ACKNOWLEDGEMENTS}

This work was supported by the National Nature Science Foundation of China (Grant Nos. 41474004, 41461089, and 41604019); the Open Fund of Guangxi Key Laboratory of Spatial Information and Geomatics (Grant No. 15-140-07-32); the Key Laboratory for Digital Land and Resources of Jiangxi Province, East China University of Technology (Grant No. DLLJ201711).

\section{REFERENCES}

Amelung, F., Galloway, D.L., Bell, J.W., Zebker, H.A., Laczniak, R.J., 1999. Sensing the ups and downs of Las Vegas: InSAR reveals structural control of land subsidence and aquifersystem deformation. Geology, 27, pp. 483-486.

Anell, I., Thybo, H., Artemieva, I.M., 2009. Cenozoic uplift and subsidence in the North Atlantic region: Geological evidence revisited. Tectonophysics, 474, pp. 78-105.

Baldi, P., Casula, G., Cenni, N., Loddo, F., Pesci, A., 2009. GPS-based monitoring of land subsidence in the Po Plain (Northern Italy). Earth Planet. Sc. Lett, 288, pp. 204-212.

Bardi, F., Frodella, W., Ciampalini, A., 2014. Integration between ground-based and satellite SAR data in landslide mapping: The San Fratello case study. Geomorphology, 223, pp. 45-60.

Biswas, K., Chakravarty, D., Mitra, P., Misra, A., 2017. SpatialCorrelation Based Persistent Scatterer Interferometric Study for Ground Deformation. J. Indian Soc. Remote, 45, pp. 1-14.

Carmelo, G., Giulia, B., 2010. An interferometric radar for noncontact measurement of deflections on civil engineering structures: laboratory and full-scale tests. Structure \& Infrastructure Engineering, 6(5), pp. 521-534.

Carminati, E., Martinelli, G., 2002. Subsidence rates in the Po Plain, northern Italy: the relative impact of natural and anthropogenic causation. Eng. Geol, 66, pp. 241-255.

Chan, W.S., Y.L. Xu, X.L. Ding, and W.J. Dai., 2006. An integrated GPS-accelerometer data processing technique for structural deformation monitoring. Journal of Geodesy, vol. 80 (12), pp. 705-719.

Chaussard, E., Amelung, F., Abidin, H., Hong, S.H., 2013. Sinking cities in Indonesia: ALOS PALSAR detects rapid subsidence due to groundwater and gas extraction. Remote Sens. Environ, 128, pp. 150-161.

Farrar, C. R., Darling, T. W., Migliori, A., 1999. Microwave interferometer for non-contact vibration measurements on large 
structures. Mechanical Systems \& Signal Processing, 13(2), pp. 241-253.

Gentile, C., and Bernardini, G., 2010. An interferometric radar for non-contact measurement of deflections on civil engineering structures: laboratory and full-scale tests. Structure \& Infrastructure Engineering, 6(5), pp. 521-534.

Macedo, K. A. C. D., Ramos, F. L. G., Gaboardi, C., 2017. A Compact Ground-Based Interferometric Radar for Landslide Monitoring: The Xerém Experiment. IEEE Journal of Selected Topics in Applied Earth Observations \& Remote Sensing, 10(3), pp. 975-986.

Monserrat, O., Crosetto, M., and Luzi, G., 2014. A review of ground-based SAR interferometry for deformation measurement. ISPRS Journal of Photogrammetry \& Remote Sensing, 93 (7), pp. $40-48$.

Motagh, M., Walter, T.R., Sharifi, M.A., Fielding, E., Schenk, A., Anderssohn, J., Zschau, J., 2008. Land subsidence in Iran caused by widespread water reservoir overexploitation. Geophys. Res. Lett, 35, L16403.

Pieraccini, M., Dei, D., and Mecatti, D., 2013. Interferometric radar for testing large structures with a built-in seismic accelerometer. Sensors \& Actuators A Physical, 204 (204), pp. 25-30.

Poland, M., Bürgmann, R., Dzurisin, D., Lisowski, M., Marsterlark, T., Owen, S., Fink, J., 2006. Constraints on the mechanism of long-term, steady subsidence at Medicine Lake volcano, northern California, from GPS, leveling, and InSAR. $J$. Volcanol. Geotherm. Res, 150, pp. 55-78.

Psimoulis, P., Ghilardi, M., Fouache, E., Stiros, S., 2007. Subsidence and evolution of the Thessaloniki plain, Greece, based on historical levelling and GPS data. Eng. Geol, 90, pp. 55-70.

Rödelsperger, S., Becker, M., Gerstenecker, C., 2010. Digital elevation model with the ground-based SAR IBIS-L as basis for volcanic deformation monitoring. Journal of Geodynamics, 49(3-4), pp. 241-246.

Takahashi, K., Matsumoto, M., and Sato, M., 2013. Continuous Observation of Natural-Disaster-Affected Areas Using GroundBased SAR Interferometry. IEEE Journal of Selected Topics in Applied Earth Observations \& Remote Sensing, 6 (3), pp. 12861294.

Tarchi, D., Rudolf, H., Pieraccini, M., 2000. Remote monitoring of buildings using a ground-based SAR: Application to cultural heritage survey. International Journal of Remote Sensing, 21(18), pp. 3545-3551.

Ventisette, C. D., Casagli, N., Fortuny-Guasch, J., 2012. Ruinon landslide (Valfurva, Italy) activity in relation to rainfall by means of GBInSAR monitoring. Landslides, 9(4), pp. 497509.

Zhou L., Guo J., Hu J., 2017. Wuhan Surface Subsidence Analysis in 2015-2016 Based on Sentinel-1A Data by SBASInSAR. Remote Sensing, 9(10), pp. 982. 